\title{
Vitamin D Status and Its Determinants in a Paediatric Population in Norway
}

\author{
Mads N Holten-Andersen ${ }^{1,2, *}$, Johanne Haugen ${ }^{3}$, Ingvild Oma ${ }^{3}(-)$ and Tor A Strand ${ }^{4,5}(\mathbb{D}$ \\ 1 Department of Paediatrics, Lillehammer Hospital, Innlandet Hospital Trust, 2626 Lillehammer, Norway \\ 2 Department of Clinical Medicine, Faculty of Medicine, University of Oslo, 0316 Oslo, Norway \\ 3 Department of Medical Microbiology, Innlandet Hospital Trust, 2626 Lillehammer, Norway; \\ Johanne.Haugen@sykehuset-innlandet.no (J.H.); ingvild.oma@gmail.com (I.O.) \\ 4 Centre for Intervention Science in Maternal and Child Health, Centre for International Health, \\ University of Bergen, P.O. Box 7800, 7803 Bergen, Norway; tors@me.com \\ 5 Department of Research, Innlandet Hospital Trust, 2381 Brumunddal, Norway \\ * Correspondence: madsn.holten-andersen@sykehuset-innlandet.no; Tel.: +47-61272013
}

Received: 8 April 2020; Accepted: 9 May 2020; Published: 12 May 2020

\begin{abstract}
Recommendations for sufficient vitamin D intake in children were recently revised in Norway. However, optimal levels of vitamin D are still debated and knowledge on supplementation and vitamin D levels in healthy children in Norway is scarce. Therefore, we measured the plasma-concentration of 25-hydroxyvitamin D (25(OH)D) in children and adolescents attending the outpatient paediatric clinics in Innlandet Hospital Trust, Norway during two consecutive years (2015-2017). We recruited 301 children and adolescents aged 5 months to 18 years (mean 7.8, SD 4.4 years) for the study and obtained sample material for 25(OH)D measurements from $295(98 \%)$. Information on diet, vitamin $\mathrm{D}$ supplementation, sun exposure, ethnicity, parental education and general health was collected by questionnaire. $25(\mathrm{OH}) \mathrm{D}$ levels were analysed and determinants for $25(\mathrm{OH}) \mathrm{D}$ were estimated by linear regression. $1.0 \%$ of the children had deficient levels $(25(\mathrm{OH}) \mathrm{D}$ $<25 \mathrm{nmol} / \mathrm{L}$ ) and $21.0 \%$ had insufficient levels $(25-50 \mathrm{nmol} / \mathrm{L}) .25(\mathrm{OH}) \mathrm{D}$ levels ranging from 50 to $75 \mathrm{nmol} / \mathrm{L}$ were found among $38.3 \%$, while $39.7 \%$ had levels above $75 \mathrm{nmol} / \mathrm{L}$. The mean $25(\mathrm{OH}) \mathrm{D}$ level was $70.0 \mathrm{nmol} / \mathrm{L}$ (SD 23.4, range 17-142 nmol/L) with a significant seasonal variation with lowest levels in mid-winter and highest in late summer. In addition to seasonal variation independent determinants for 25(OH)D-levels were age of the child, parental ethnicity, vitamin D supplementation and soda consumption. Along with parental ethnicity other than Nordic, age was the strongest determinant of $25(\mathrm{OH}) \mathrm{D}$, with adolescents having the lowest levels.
\end{abstract}

Keywords: vitamin D; 25(OH)D; child; adolescent; age; ethnicity

\section{Introduction}

Although a well-defined threshold value for 25-hydroxyvitamin D $(25(\mathrm{OH}) \mathrm{D})$ is lacking, it is established that severe vitamin D deficiency increases the risk for hypocalcaemia and impaired bone health in children, such as rickets and osteomalacia [1]. In recent years there has been an increased interest in measuring vitamin $\mathrm{D}$ for other indications as well, most likely as a result of indications of possible associations between mild vitamin D deficiency and other health outcomes, such as immunologic, infectious, cardiovascular, and cancer diseases in epidemiological studies [2]. Despite decades of research on vitamin $\mathrm{D}$, questions still remain unanswered regarding mechanisms and possible causality in the putative non-calcemic effects of vitamin D [2], resulting in an on-going debate on optimal vitamin D status and modalities for vitamin D measurement. In the latest Nordic guidelines (from 2012) for intake of nutrients, the recommended intake of vitamin D was increased 
for children above 2 years of age in order to target a sufficient vitamin D concentration, defined as $25(\mathrm{OH}) \mathrm{D}>50 \mathrm{nmol} / \mathrm{L}$ [3]. In 2008, a systematic review of existing studies of 25(OH)D status among healthy Norwegians in different age groups was published [4]. For children and adolescents existing studies were relatively few and most were characterized by older date, small sample size or limited age span (infants, toddlers, adolescents) [4]. Earlier studies from the 1980s have reported a high prevalence of vitamin D deficiency among exclusively breastfed infants in Norway [5] as well as vitamin $\mathrm{D}$ insufficiency among older children and adolescents at the end of the winter season [6]. A more recent study from Troms $\varnothing\left(69^{\circ} \mathrm{N}\right)$ in Northern Norway including 890 adolescents aged $15-18$ years reported that $25(\mathrm{OH}) \mathrm{D}$ deficiency or insufficiency was prevalent among $60.2 \%$ of the participant and more frequent in boys [7]. Determinant for 25(OH)D among the adolescents included vitamin supplementation, physical activity, sunbathing on holidays and use of solarium [7]. Still, detailed knowledge on current 25(OH)D levels in children and adolescents in different age groups in Norway is lacking. Furthermore, detailed information on factors with potential influence on $25(\mathrm{OH}) \mathrm{D}$ levels in Norwegian children and adolescents including seasonal variation, diet, vitamin D supplementation, sun-exposure and ethnicity is needed. In this paper, we describe $25(\mathrm{OH}) \mathrm{D}$ levels and possible determinants in a paediatric population, consisting of children and adolescents aged 5 months- 18 years, attending the outpatient paediatric clinics at Innlandet Hospital Trust, Norway, during two consecutive years (2015-2017).

\section{Materials and Methods}

\subsection{Study Design and Enrolment of Study Subjects}

This cross-sectional study was undertaken at the paediatric departments of Innlandet Health Trust from January 2015 until March 2017. The study had two objectives: (1) to evaluate the association between $25(\mathrm{OH}) \mathrm{D}$ levels and susceptibility of lower respiratory tract infection in children less than five years of age using case-control design, and (2) to survey 25(OH)D levels in children and adolescents in the Innlandet region, Norway. The sample size for the cross sectional component assumed a proportion of deficiency of $50 \%$. For an absolute precision of $5 \%(95 \% \mathrm{CI})$ we needed a sample of nearly 400. Data from the case-control study have not yet been published and the case component, consisting of children hospitalized because of acute lower respiratory tract infection, will not be further discussed in this paper. The participants in the control group were enrolled at the paediatric outpatient clinics at Lillehammer, Gjøvik, and Elverum $\left(61^{\circ} \mathrm{N}\right)$, Norway. Eligible for inclusion were 5 months-18 years old children and adolescents attending the outpatient clinics. Prerequisites for inclusion were informed written parental consent and the child had to have a blood test taken as part of the paediatric evaluation. Fulfilment of inclusion criteria was at the discretion of the attending paediatrician at the paediatric outpatient clinic. Exclusion criteria included presence of acute lower respiratory tract infection or other acute infection, chronic severe liver, kidney, heart or lung disease, chronic severe metabolic or nutritional disorders or oncologic disease. 40.9\% (123 of 301) of the participants in the control group had a non-excluding chronic disease. A variety of diagnoses were represented including congenital heart disease, allergies, neurologic, nephrologic, gastrointestinal, endocrine and dermatologic disorders, with the most frequent being type 1 diabetes (21) and asthma (24). An individual project number was assigned to each patient, which along with date of inclusion, date of birth, and gender were registered. Ethical clearances and approval of consent procedure were obtained from the Regional Committee for Medical and Health Research Ethics in the southeast part of Norway, REC Southeast (2015/199/REK sør-øst B). Informed written consent was obtained from at least one parent of all recruited children. The implementation of all aspects of the projects was in agreement with the International Ethical Guidelines for Research Involving Human Subjects as stated in the latest version of the Helsinki Declaration. 


\subsection{Background Data and Anthropometrics}

Age and gender were registered for all children and adolescents enrolled in the study. Anthropometrics, including height/length $(\mathrm{cm})$ and weight $(\mathrm{kg})$, were measured by a paediatric nurse in the outpatient clinic on the day of inclusion using standardized methods and scales. Height was measured to the nearest millimeter and weight to the nearest $100 \mathrm{~g}$ [8]. Supplemental health information was obtained using a questionnaire completed by parents of enrolled children. Children above 12 years of age were encouraged to complete the questionnaire with their parents.

\subsection{Questionnaire}

Questions included parental education (9 years of primary school, 9 years of primary school +1-2 years high school, 9 years of primary school +3 years high school, higher education college, higher education university), current parental employment (fulltime job ( $>30 \mathrm{~h} / \mathrm{week}$ ), part time job (<30 h/week), unemployed/seeking job, student, working at home, disability support, other), numbers of smokers in the household (none, 1, 2, 3, >3), parental ethnicity (maternal and paternal country of origin), asthma of the child (not having asthma, mild asthma, moderate asthma, uses asthma medication when needed, uses asthma medication daily, does not use asthma medication), vitamin D supplementation (daily, 4-6 times/week, 1-3 times/week, 1-3 times/month, seldom/never), intake of fatty fish, vegetables, fruit, sweets, and soda drinks (daily, 4-6 times/week, 1-3 times/week, 1-2 times/fortnight, 1-2 times/month, seldom/never), daily time spent outside with sun exposure of the skin during the summer months (a lot, moderate, little, almost never), use of sunscreen (always, often, seldom, never), and previous lower respiratory tract infection requiring antibiotic treatment (yes, no). In accordance with our "a priori" plan for interpretation of the data some of the descriptive ordinal variables were dichotomized in order to perform meaningful analyses. Vitamin D supplementation was dichotomized to yes/no: no including "seldom/never" and yes including remaining categories. Dietary intake of fatty fish was dichotomized to yes/no: no including seldom/never and yes including remaining categories. Intake of sweets and soda were dichotomized to weekly/not weekly: weekly including "daily", "4-6 times/week" and "1-3 times/week", not weekly including remaining categories. Education of mother/father was dichotomized to higher/lower education: "higher education" including college and university with the remaining groups designated "lower education". Parental ethnicity was categorized into the following three groups: both parents of Nordic origin, one parent of Nordic origin, no parent of Nordic origin. Smoking in the household and asthma were dichotomized to yes/no. Sun-exposure was dichotomized as a lot/little: those answering "a lot" in one category and the remaining (moderate, little, almost never) into a group designate "little". Sunscreen use was dichotomized to yes/no: those using sunscreen always and often in one category ("yes") and those reporting use seldom and never in the other ("no"). Different categories of dichotomization for both vitamin D supplementation and fatty fish intake were explored but were not found to affect the results of the regression analyses.

\subsection{Blood Samples and Laboratory Analyses}

Blood (0.5 mL plasma) was drawn as capillary samples in the infants and toddlers and by venipuncture in the older children. Plasma was separated from blood cells by centrifugation at $2500 \mathrm{G}$ followed by storage at $4{ }^{\circ} \mathrm{C}$ until analysis the same day. P-25(OH)D-concentration was measured using the protein binding assay Roche Elecsys vitamin D total at the Department of Laboratory Medicine at Innlandet Health Trust along with other blood-test parameters requested by the doctor involved according to hospital routines. The Roche Elecsys vitamin $\mathrm{D}$ total assay has a functional sensitivity below $15 \mathrm{nmol} / \mathrm{L}$ and within-run CVs of $\leq 6 \%$ and between-run CVs of $\leq 8 \%$ [9]. Month of the year at which the blood sampling had occurred was registered for all recruited children. In linear regression analyses month of the year was dichotomized into season; summer May-October, winter November-April. 


\subsection{Definition of Vitamin D Status}

In this paper we use the cut-off $25(\mathrm{OH}) \mathrm{D}>50 \mathrm{nmol} / \mathrm{L}$ for vitamin $\mathrm{D}$ sufficiency, which is in line with the 5th edition of the Nordic Nutrition Recommendations [10]. This cut-off also corresponds to the "Global Consensus Recommendations on Prevention and Management of Nutritional Rickets" [11] from 2016, the Institute of Medicine (IOM) from 2011 [12], and The Paediatric Endocrine Society from 2008 [13]. To reflect another commonly used cut-off for vitamin D insufficiency referred to in the literature, we also report the cut-off $<75 \mathrm{nmol} / \mathrm{L}$ [14]. 25(OH)D levels between 25 and 50 were thus regarded as insufficiency of vitamin $\mathrm{D}$ in our study. Definitions of deficiency also vary. In the Nordic countries vitamin D deficiency is defined as $25(\mathrm{OH}) \mathrm{D}<25 \mathrm{nmol} / \mathrm{L}$, which is therefore used in this publication. A cut-off of $30 \mathrm{nmol} / \mathrm{L}$ is often used in other European countries, whereas others use a cut-off at $50 \mathrm{nmol} / \mathrm{L}[14]$.

\subsection{Statistical Analyses}

Figures of predicted mean $25(\mathrm{OH}) \mathrm{D}$ and $\mathrm{CI}$ according to month of the year and age were generated using two-way fpfit-analyses. Associations between potential determinants and 25(OH)D levels were investigated in unadjusted and adjusted linear regression analyses. A step-wise manual selection process was used for evaluating determinants of 25(OH)D in multiple linear regression models [15]. The following candidate variables were included in this process: age, gender, maternal education (higher/lower), paternal education (higher/lower), parental ethnicity (both Nordic/one Nordic/none Nordic), tobacco smoke in the household (no/yes), intake of vitamin D supplements at least monthly (no/yes), intake of fatty fish at least monthly (no/yes), intake of sweets weekly (no/yes), intake of soda weekly (no/yes), sun-exposure (little/a lot), sunscreen use (no/yes), asthma (no/yes), previous infection requiring antibiotic treatment (no/yes), season of the year (summer/winter). Assessment for multicollinearity was performed using variance inflation factor (VIF). Test for interaction between parental ethnicity and vitamin D supplementation was done in additional models. Significance levels were set at 5\%. Statistical analyses were carried out using SPSS Statistics for Windows, Version 23.0.0.2 Armonk, NY: IBM Corp and STATA 15.0 software (STATA).

\section{Results}

301 children were included (Table 1). Their mean age was 93.1 (SD 52.3) months corresponding to 7.8 (SD 4.4, range 0.42-17.8) years. Their mean weight was 30.2 (SD 18.1) kg and mean height 123.8 (SD 31.4) cm. For $267(88.7 \%)$ of the children both parents had Nordic ethnicity, for $23(7.6 \%)$ one parent had Nordic ethnicity and for 11 (3.7\%) neither of the parents had Nordic ethnicity. The percentage of children receiving vitamin D supplementation was $61.9 \%$, with $70.6 \%$ for those with one or both parents with other ethnicity than Nordic. Intake of fatty fish at least once a week occurred in $47.6 \%$, with a higher fraction of $58.8 \%$ among those with one or both parents of non-Nordic ethnicity. Consumption of soda at least weekly was reported by $52.5 \%$. Sun-exposure throughout the summer months was reported as "a lot" by $60.9 \%$, and $89.2 \%$ reported use of sunscreen. Living in households where smoking was reported by $19.4 \%$ of children; $25.6 \%$ had asthma and $26.2 \%$ had previous experience of one or several episodes of lower respiratory tract infection requiring antibiotic treatment.

25(OH)D was measured in 295 children. In 6 children 25(OH)D was not measured due to too little sample material (4 children) or having been included in the study, but not having blood sample taken after all ( 2 children). 66\% (196/295) of the participants were included during winter (November-April) corresponding to the seasonal variation in the number of children attending the out-patient clinics of Innlandet Health Trust, with the lowest numbers in mid-summer. The mean (SD) 25(OH)D-concentration was $70.0(23.4) \mathrm{nmol} / \mathrm{L}$ ranging from 17 to $142 \mathrm{nmol} / \mathrm{L}$ (Table 2). There were substantial differences in $25(\mathrm{OH}) \mathrm{D}$ levels between the summer and the winter months with the lowest levels measured in December (mean \pm SD: $57.7 \pm 12.5 \mathrm{nmol} / \mathrm{L}$ ) and the highest in August (mean \pm 
SD: $96.9 \pm 19.1 \mathrm{nmol} / \mathrm{L})$. The seasonal variation of $25(\mathrm{OH}) \mathrm{D}$ levels is illustrated in Figure 1 displaying predicted mean 25(OH)D levels with 95\% CI according to month of blood sampling.

Table 1. Child characteristics.

\begin{tabular}{lc}
\hline Characteristics & Value \\
\hline Age in years & $7.8(4.4)$ \\
Boys & $147(49.0)$ \\
Weight in kg & $30.5(18.2)$ \\
Height in cm & $125.5(28.8)$ \\
Supplements of vitamin D $\geq 1$ monthly & $182(61.9)$ \\
Fatty fish $\geq 1$ monthly & $138(47.6)$ \\
Soda consumption $\geq 1$ weekly & $149(52.5)$ \\
Both parents of Nordic ethnicity & $267(88.7)$ \\
One parent with other ethnicity than Nordic & $23(7.6)$ \\
Both parents with other ethnicity than Nordic & $11(3.7)$ \\
Mother higher education & $150(52.3)$ \\
Father higher education & $107(37.9)$ \\
Sun-exposure during summer as “a lot" & $173(60.9)$ \\
Using sunscreen always/almost always/often & $256(89.2)$ \\
Smoking in the household & $56(19.4)$ \\
Asthma & $73(25.6)$ \\
ALRI requiring antibiotic treatment & $75(26.2)$ \\
\hline
\end{tabular}

Variables reported by mean (SD) or $\mathrm{n}(\%)$. ALRI-acute lower respiratory infections. Number of $n$ for each variable displayed ranged from 275 to 300 and were always above $91 \%$ of the total 301.

Table 2. Plasma 25(OH)D levels by month in a population of Norwegian children.

\begin{tabular}{lcccccc}
\hline Month & $\boldsymbol{n}$ & $\begin{array}{c}\text { Mean } \mathbf{2 5 ( O H ) D} \\
\text { (SD) in nmol/L }\end{array}$ & $\begin{array}{c}<\mathbf{2 5} \\
\boldsymbol{n} \mathbf{( \% )}\end{array}$ & $\begin{array}{c}\mathbf{2 5 - 5 0} \\
\boldsymbol{n} \mathbf{( \% )}\end{array}$ & $\begin{array}{c}\mathbf{5 0 - 7 5} \\
\boldsymbol{n} \mathbf{( \% )}\end{array}$ & $\begin{array}{c}\mathbf{2 5 ( O H ) D} \geq \mathbf{7 5} \\
\boldsymbol{n} \mathbf{( \% )}\end{array}$ \\
\hline January & 60 & $61.4(21.5)$ & $2(3.3)$ & $16(26.7)$ & $29(48.3)$ & $13(21.7)$ \\
February & 51 & $67.1(23.1)$ & 0 & $15(29.4)$ & $20(39.2)$ & $16(31.4)$ \\
March & 37 & $68.6(23.9)$ & 0 & $9(24.3)$ & $15(40.5)$ & $13(35.1)$ \\
April & 29 & $64.7(24.1)$ & 0 & $11(37.9)$ & $7(24.1)$ & $11(37.9)$ \\
May & 29 & $72.4(22.3)$ & 0 & $5(17.2)$ & $9(31.0)$ & $15(51.7)$ \\
June & 27 & $82.3(24.4)$ & $1(3.7)$ & $2(7.4)$ & $8(29.6)$ & $16(59.2)$ \\
July & 5 & $91.6(31.2)$ & 0 & 0 & $1(20)$ & $4(80)$ \\
August & 8 & $96.9(19.1)$ & 0 & 0 & 0 & $8(100)$ \\
September & 9 & $79.4(11.6)$ & 0 & 0 & $3(33.3)$ & $6(66.7)$ \\
October & 21 & $73.9(15.9)$ & 0 & $1(4.8)$ & $10(47.6)$ & $10(47.6)$ \\
November & 12 & $76.3(23.5)$ & 0 & $1(8.3)$ & $6(50.0)$ & $5(41.7)$ \\
December & 7 & $57.7(12.5)$ & 0 & $2(28.6)$ & $5(71.4)$ & 0 \\
\hline
\end{tabular}

Only $3(1 \%)$ children were vitamin D deficient $(25(\mathrm{OH}) \mathrm{D}<25 \mathrm{nmol} / \mathrm{L})$. All 3 children were above 12 years of age and one had parental ethnicity other than Nordic. The prevalence of vitamin D insufficiency was higher among the older children and adolescents than among the younger children (Table 3). While only $14.7 \%$ of the children below 6 years of age had insufficient levels $(25(\mathrm{OH}) \mathrm{D}<$ $50 \mathrm{nmol} / \mathrm{L}$ ), insufficiency (including deficiency) was present in $47.5 \%$ of the children aged 12 years or older. Both the reported intake of vitamin D supplementation and self-reported sun-exposure tended to be inversely related to age with lower prevalence among the children older than 12 years compared to the younger children with exception of sun-exposure in those $<2$ years of age. 


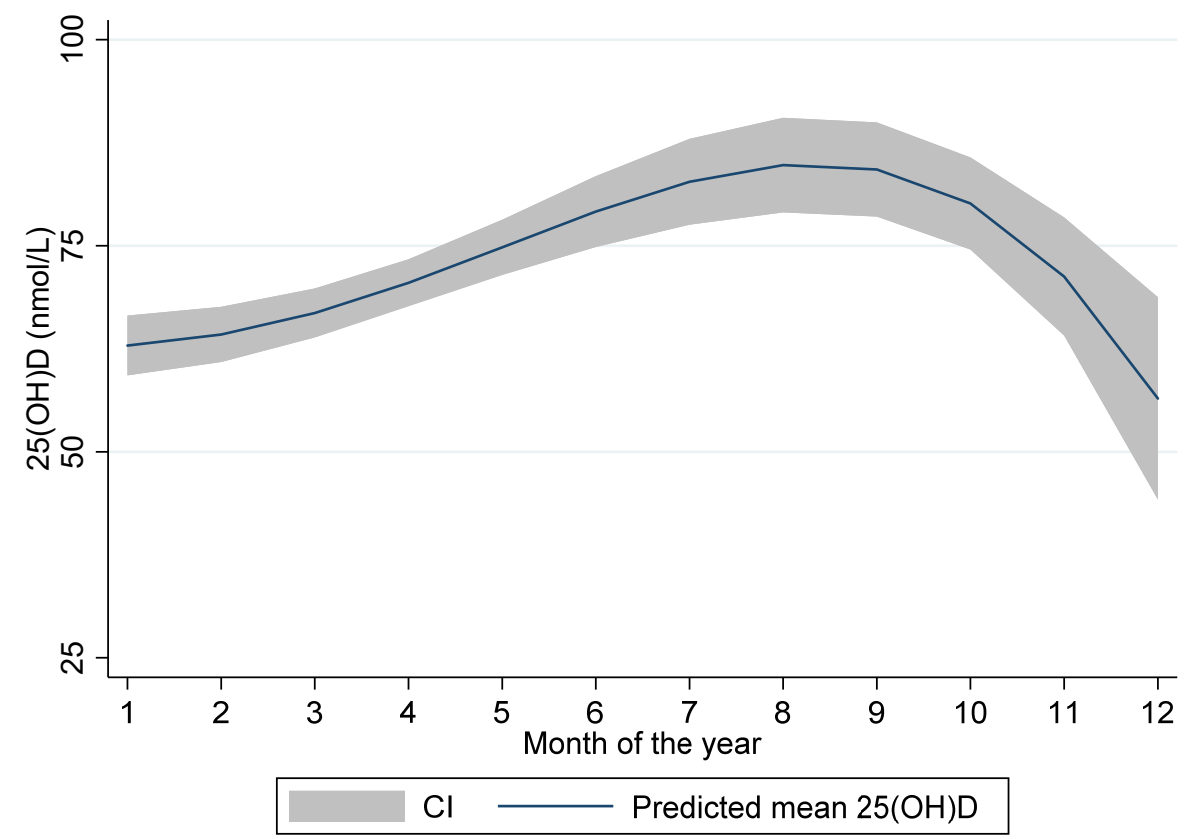

Figure 1. Plasma 25(OH)D levels according to month of the year in Norwegian children. Predicted mean and $95 \%$ CI during month 1 (January) to 12 (December).

Table 3. 25(OH)D levels, vitamin D supplementation and sun-exposure by age groups.

\begin{tabular}{|c|c|c|c|c|c|c|c|}
\hline Age & $\begin{array}{l}\text { 25(OH)D Mean } \\
\text { (SD) nmol/L }\end{array}$ & $\begin{array}{c}25(\mathrm{OH}) \mathrm{D} \\
<25 \\
n(\%)\end{array}$ & $\begin{array}{c}25(\mathrm{OH}) \mathrm{D} \\
25-50 \\
n(\%)\end{array}$ & $\begin{array}{c}25(\mathrm{OH}) \mathrm{D} \\
50-75 \\
n(\%)\end{array}$ & $\begin{array}{c}25(\mathrm{OH}) \mathrm{D} \\
\geq 75 \\
n(\%)\end{array}$ & $\begin{array}{c}\text { Vitamin D } \\
\text { Supplementation } \\
n(\%)\end{array}$ & $\begin{array}{c}\text { Sun-Exposure } \\
\text { "a lot" } \\
n(\%)\end{array}$ \\
\hline$<2$ years & $89.5(24.8)^{a}$ & 0 & $2(8.3)$ & $3(12.5)$ & 19 (79.2) & $22(88.0)^{b}$ & $7(30.4)^{c}$ \\
\hline $2-6$ years & $75.8(24.2)^{d}$ & 0 & $15(16.3)$ & $27(29.4)$ & $50(54.4)$ & $54(59.3)^{\mathrm{e}}$ & $58(67.4)^{f}$ \\
\hline 6-12 years & $68.7(18.9) \mathrm{g}$ & 0 & $20(16.7)$ & $64(53.3)$ & $36(30)$ & $75(63.0)^{h}$ & $77(65.2)^{\mathrm{i}}$ \\
\hline $12-18$ years & $55.8(21.4)^{j}$ & $3(5.1)$ & $25(42.4)$ & 19 (32.2) & $12(20.3)$ & $29(50.9)^{k}$ & $29(52.7)^{1}$ \\
\hline All & $70.0(23.4) \mathrm{m}$ & $3(1.0)$ & $62(21.0)$ & $113(38.3)$ & 117 (39.7) & $182(61.9)^{n}$ & $171(60.6)^{\circ}$ \\
\hline
\end{tabular}

a: $n=24$, b: $n=25$ c: $n=23$, d: $n=92$, e: $n=91, \mathrm{f}: n=86, \mathrm{~g}: n=120, \mathrm{~h}: n=119$, i: $n=118, \mathrm{j}: n=59, \mathrm{k}: n=57$, l: $n=55, \mathrm{~m}: n=295, \mathrm{n}: n=292, \mathrm{o}: n=282$.

Figure 2 illustrates the age-related levels of $25(\mathrm{OH}) \mathrm{D}$ with predicted mean levels and $95 \% \mathrm{CI}$ of 25(OH)D according to age displayed.

Age, weekly soda consumption and winter season were inversely associated with 25(OH)D, whereas vitamin D supplementation, Nordic parental ethnicity and summer season were positively associated with 25(OH)D-concentration (Table 4). Compared with children of parents where both had non-Nordic ethnicity 25(OH)D levels were $15.5 \mathrm{nmol} / \mathrm{L}$ higher in children with one parent with Nordic ethnicity and $24.5 \mathrm{nmol} / \mathrm{L}$ higher in children with both parents with Nordic ethnicity. Children who had 25(OH)D measured during summer had on average $10.2 \mathrm{nmol} / \mathrm{L}$ higher levels than those measured during winter. Children reported to use vitamin D supplementation had $8.84 \mathrm{nmol} / \mathrm{L}$ higher $25(\mathrm{OH}) \mathrm{D}$ levels on average than children not using supplementation. On average, $25(\mathrm{OH}) \mathrm{D}$ levels decreased by $1.75 \mathrm{nmol} / \mathrm{L}$ for an increase in age of 1 year. Finally, children reported to have weekly consumption of soda had on average $5.47 \mathrm{nmol} / \mathrm{L}$ lower $25(\mathrm{OH}) \mathrm{D}$ levels than those who did not. Taken together, the variables age, vitamin $\mathrm{D}$ supplementation, parental ethnicity, weekly soda consumption and season of the year predicted $27 \%$ of the variation in $25(\mathrm{OH}) \mathrm{D}$-concentration in the regression analyses. 


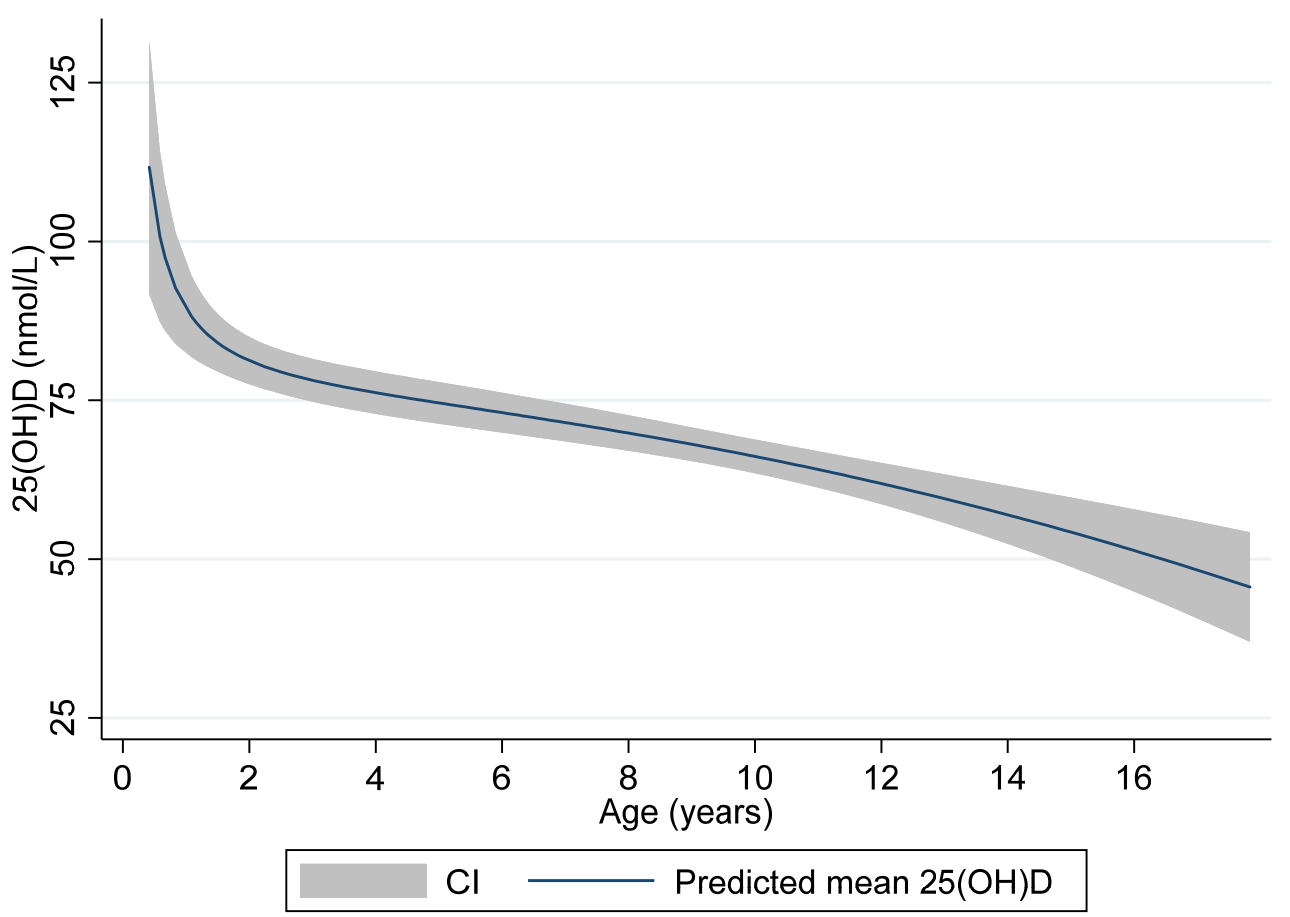

Figure 2. Plasma 25(OH)D levels and age. Predicted mean and $95 \% \mathrm{CI}$ in relation to age in years.

Table 4. Determinants of 25(OH)D levels in Norwegian children.

\begin{tabular}{|c|c|c|c|c|c|c|c|c|}
\hline \multirow[t]{2}{*}{ Predictor } & \multirow[t]{2}{*}{$n$} & \multicolumn{3}{|c|}{ Crude $(n=295)$} & \multicolumn{4}{|c|}{ Adjusted $(n=280)$} \\
\hline & & Coeff & $95 \% \mathrm{CI}$ & $p$ & Coeff & $95 \% \mathrm{CI}$ & $p$ & Beta \\
\hline Age (years) & 295 & -2.14 & -2.71 to -1.57 & $<0.001$ & -1.75 & -2.33 to -1.16 & $<0.001$ & -0.32 \\
\hline Vitamin D supplement, no & & ref & & & & & & \\
\hline Vitamin D supplement, yes & 289 & 10.2 & 4.75 to 15.7 & $<0.001$ & 8.84 & 3.88 to 13.8 & 0.001 & 0.18 \\
\hline Parental ethnicity, non-Nordic & & ref & & & & & & \\
\hline Parental ethnicity, one Nordic & & 10.8 & -6.03 to 27.6 & 0.208 & 15.5 & 0.55 to 30.4 & 0.042 & 0.17 \\
\hline Parental ethnicity, both Nordic & 295 & 18.8 & 4.77 to 32.8 & 0.009 & 24.5 & 12.1 to 36.9 & $<0.001$ & 0.33 \\
\hline Soda weekly intake, no & & ref & & & & & & \\
\hline Soda weekly intake, yes & 280 & -9.66 & -15.1 to -4.26 & $<0.001$ & -5.47 & -10.5 to -0.43 & 0.034 & -0.12 \\
\hline Summer, no & & ref & & & & & & \\
\hline Summer, yes & 295 & 13.5 & 8.07 to 19.0 & $<0.001$ & 10.2 & 5.14 to 15.3 & $<0.001$ & 0.21 \\
\hline
\end{tabular}

Age, vitamin D supplementation, parental ethnicity, soda consumption and season were significantly associated with $25(\mathrm{OH}) \mathrm{D}$ levels in both unadjusted and adjusted models. All variables in Table 4 were included in the adjusted model. Adjusted R-squared $=0.27$. Coeff- unstandardized regression coefficient. Beta—standardized regression coefficient.

The remaining variables tested in the model (gender of the child, weekly intake of fatty fish (no/yes), parents with higher education (no/yes), self-reported sun-exposure (little/a lot), sunscreen use (no/yes), smoking in the household (no/yes), asthma (no/yes) and previous lower respiratory tract infection requiring antibiotic treatment (no/yes)) were not significantly associated with $25(\mathrm{OH}) \mathrm{D}$, neither in the univariate nor in the multivariate analyses. No indication of multi-colliarities or significant interactions were found between tested variables.

\section{Discussion}

Only $1.0 \%$ of the children in this sample of children from Innlandet County, Norway, were vitamin D deficient $(25(\mathrm{OH}) \mathrm{D}<25 \mathrm{nmol} / \mathrm{L})$, whereas $21.0 \%$ had insufficient levels of vitamin $\mathrm{D}(25(\mathrm{OH}) \mathrm{D}$ $25-50 \mathrm{nmol} / \mathrm{L}$ ). Deficiency was only seen in teenagers (12-18 years). The presence of low vitamin D 
status was more prevalent in the teenagers than in the younger children; $42.4 \%$ of the teenagers in our study had insufficient levels of $25(\mathrm{OH}) \mathrm{D}$, compared to $8.3 \%, 16.3 \%$ and $16.7 \%$ in the age-groups $<2$, 2-6 and 6-12 years, respectively.

Previous data on vitamin D status in younger children in Norway is scarce. A study among 249 one-year-olds from Oslo reported a prevalence of vitamin D insufficiency of 34\% during April-June 2000 for breastfed children, with a significant difference between children receiving vitamin D supplementation (14\%) and those who did not (38\%) [6]. Within the same study, similar levels in 227 two-year-olds were reported between March and June 2001 [6]. Almost all the children $<2$ years of age received some kind of vitamin D supplementation in our study and this may be one of the reasons why vitamin $\mathrm{D}$ levels were higher in this population.

For the children in our study, the prevalence of deficient and insufficient vitamin D levels were very similar to multi-centre-data from the U.S. National Health and Nutrition Examination Survey (NHANES) 2001-2006. In a sample of 4558 US children (aged 1-11 years), 1\% of the children were found to have vitamin $\mathrm{D}$ deficiency (defined as $25(\mathrm{OH}) \mathrm{D}<25 \mathrm{nmol} / \mathrm{L}$ ), $18 \%$ had vitamin $\mathrm{D}$ insufficiency (defined as 25(OH)D $<50 \mathrm{nmol} / \mathrm{L}$ ), and 69\% had levels $<75 \mathrm{nmol} / \mathrm{L}$ [16]. The mean 25(OH)D level was $68 \mathrm{nmol} / \mathrm{L}$ in this multi-centre study, and older age and Hispanic/non-Hispanic or black ethnicity was inversely associated with $25(\mathrm{OH})$ D-levels.

The lowest levels of $25(\mathrm{OH}) \mathrm{D}$ were found in the age-category $>12$ years in our study. This finding is also consistent with previous studies. In a study from 1982, adolescents from Bergen, Norway were at risk of vitamin D insufficiency, especially in late winter. The lowest levels of vitamin D was found among 17 years old boys of which 50\% were found to have insufficient levels [6]. Another population-based study from 2014 among 1038 healthy adolescents in northern Norway, reported a prevalence of vitamin D insufficiency $(25(\mathrm{OH}) \mathrm{D}<50 \mathrm{nmol} / \mathrm{L})$ of $60 \%$ and a vitamin D deficiency $(25(\mathrm{OH}) \mathrm{D}<25 \mathrm{nmol} / \mathrm{L})$ of $16.5 \%$ through September to April [7]. In our study, we found that age was a strong determinant of $25(\mathrm{OH}) \mathrm{D}$, being inversely associated with vitamin $\mathrm{D}$ levels. This negative association is also reported in other studies: in children and adolescents (mean age \pm SD, 14.5 years \pm 3.1 ) from Oslo, Norway with excess body weight (mean BMI $\pm \mathrm{SD}, 29.7 \mathrm{~kg} / \mathrm{m}^{2} \pm 6.0$ ), Lagunova et al. reported prevalence of vitamin D insufficiency $(25(\mathrm{OH}) \mathrm{D}<50 \mathrm{nmol} / \mathrm{L})$ in $24 \%$ of the $13-19$ year olds but only in $4 \%$ of the 8-12 year olds [17]. Furthermore, in a recent Danish study on obesity and vitamin D status, being above the age of 14 was an independent risk factor for low vitamin D status also in the population-based control-group consisting of 2143 children and adolescents [18]. Although there is a trend towards an inverse relationship between age and sun exposure for children above 2 years of age, we did not find that self-reported sun-exposure was related to $25(\mathrm{OH}) \mathrm{D}$ levels in our study. However, we found that season of the year was a determinant for $25(\mathrm{OH}) \mathrm{D}$ levels with the lowest mean level in January and highest in August and that the prevalence of vitamin D insufficiency was highest in April and lowest in the summer months. A possible explanation for higher concentrations of vitamin D in the younger children could be a higher prevalence of vitamin D supplementation, which also was seen in our study.

An important determinant of vitamin $\mathrm{D}$ levels in our material was parental ethnicity other than Nordic, which was associated with on average 15.5 and $24.5 \mathrm{nmol} / \mathrm{L}$ lower concentrations of 25(OH)D when having one or both parents of non-Nordic ethnicity. The synthesis of vitamin D3 in the skin is reduced by pigmentation, and especially in higher latitudes with less sun-exposure, high pigmentation without intake of vitamin D sources, may be a risk factor for vitamin D deficiency. In the sub-group of children with parents with other background than Nordic in our study, approximately half of them (53\%) were from a non-Western country and thus had a higher degree of skin-pigmentation, while the others were from different European countries. One could speculate that other habits regarding sun-exposure, clothing, food, and supplementation could be possible contributors to lower vitamin D status in this sub-group compared to the ethnic Nordic group.

$61.9 \%$ of the children in our study were given vitamin D supplementation. This was higher than a previous nationwide diet survey among Norwegian school children in 4th and 8th grade from 2015, where less than half of the 9 year olds and 13 year olds reported intake of vitamin D 
supplements [19]. However, supplementation was less important than both age and parental ethnicity in our regression model. Weekly soda-consumption was the only other dietary variable that was of significant importance in our study, and since a direct relationship is unlikely, this association could possibly reflect lifestyle factors with impact on sun-exposure and/or intake of vitamin D rich sources.

There are some limitations to our study. We recruited patients from the paediatric outpatient clinics at Innlandet Hospital Trust. Participants were mostly healthy children, referred to a paediatrician because of a complaint or a symptom for which no chronic disease was found. In addition, we included some children with underlying chronic illnesses like type 1 diabetes or asthma where the disease was well regulated. The aim was to recruit as healthy children as possible, but a fundamental precondition for the implementation of the project was that no blood tests should be taken without being a part of necessary or already planned investigation. Including children outside health care was therefore not optional for our study. Sun-exposure was self-reported and estimated by use of a semi-quantitative scale with five incremental levels. Sun-exposure is a challenging variable to measure precisely, and we consider the seasonal variable a better reflection of sun-exposure. In our questionnaire, we could have included a question on average daily screen-time, which possibly could have added information to the study as discussed above. Another way of addressing quantification of sun-exposure could have been to use a time-scale in the answer options with registration of hours/week; however, we speculate that such a measure would also have been imprecise. Furthermore, it could be speculated that the semi-quantitative answer alternatives in the questionnaire could be interpreted differently by the parents, and that responses could be biased by what the parents might consider to be the right answer to a given question. More detailed information on main vitamin D containing foods could have been registered using a food frequency questionnaire; however, this was not done in our study. Our results indicated limited associations between vitamin $\mathrm{D}$ and diet, except for vitamin $\mathrm{D}$ supplementation and weekly soda consumption. A general challenge for the interpretation of research results of vitamin $D$ status is the high degree of inter-assay differences between the various methods. An underestimation of $25(\mathrm{OH}) \mathrm{D}$ was earlier reported for a similar immuno-assay [20], but to our knowledge is not known be an issue in the assay used in this study. The major strengths of this study are the relatively wide age span covering infancy to adolescence and the recruitment period (2015-2017) with inclusion and blood sampling in all months of the year allowing for evaluation of seasonal influence.

\section{Conclusions}

In this study describing 25(OH)D levels and its determinants in Norwegian children, we found that $78 \%$ of the children and adolescents enrolled had adequate levels of $25(\mathrm{OH}) \mathrm{D}(>50 \mathrm{nmol} / \mathrm{L}) .1 \%$ and $21 \%$ had deficient and insufficient $25(\mathrm{OH}) \mathrm{D}$ levels, respectively. The lowest concentrations were measured in January (mean $61.4 \mathrm{nmol} / \mathrm{L}$ ) and the highest in August (mean $96.7 \mathrm{nmol} / \mathrm{L}$ ). The prevalence of reported intake of vitamin D supplements was $61.9 \%$. Age and parental ethnicity were the strongest determinants of $25(\mathrm{OH}) \mathrm{D}$ with increasing age and non-Nordic parental ethnicity predicting lower $25(\mathrm{OH}) \mathrm{D}$ levels. Vitamin D supplementation, season of the year and weekly soda consumption were also found to be independently associated with 25(OH)D levels. Prevalence of vitamin D insufficiency was highest among the adolescents and deficiency was only found in this age-group.

Author Contributions: Conceptualization, funding acquisition, investigation, resources, project administration, data curation M.N.H.-A., T.A.S., J.H. Methodology, formal analysis, visualization, writing-review \& editing: M.N.H.-A., J.H., I.O., T.A.S. Writing-original draft: M.N.H.-A., J.H., I.O. Supervision: M.N.H.-A., T.A.S. All authors have read and agreed to the published version of the manuscript.

Funding: Funder of the project was The Department of Research, Innlandet Health Trust, Norway (grant number 150263).

Conflicts of Interest: All authors declare that they have no conflicts of interests. 


\section{References}

1. Cranney, A.; Horsley, T.; O’Donnell, S.; Weiler, H.; Puil, L.; Ooi, D.; Atkinson, S.; Ward, L.; Moher, D.; Hanley, D.; et al. Effectiveness and safety of vitamin D in relation to bone health. Evid. Rep. Technol. Assess Full Rep 2007, 158, 1-235.

2. Theodoratou, E.; Tzoulaki, I.; Zgaga, L.; Ioannidis, J.P. Vitamin D and multiple health outcomes: Umbrella review of systematic reviews and meta-analyses of observational studies and randomised trials. BMJ 2014, 348, g2035. [CrossRef] [PubMed]

3. Nordic Nutrition Recommendations 2012. Available online: http://dx.doi.org/10.6027/Nord2014-002 (accessed on 30 April 2020).

4. Holvik, K.; Brunvand, L.; Brustad, M.; Meyer, H.E. Vitamin D status in the Norwegian population. In Solar Radiation and Human Health; Bjertness, E., Ed.; The Norwegian Academy of Science and Letters: Oslo, Norway, 2008.

5. Markestad, T. Effect of season and vitamin D supplementation on plasma concentrations of 25-hydroxyvitamin D in Norwegian infants. Acta. Paediatr. Scand. 1983, 72, 817-821. [CrossRef] [PubMed]

6. Meyer, H.; Brunvand, L.; Brustad, M.; Holvik, K.; Johansson, L.; Paulsen, J.E.; National Counsil for Nutrition; Norwegian Directorate of Health. Tiltak for å sikre en god vitamin D-status i befolkningen. IS-1408. 2006. Available online: https:/www.helsedirektoratet.no/om-oss/organisasjon/rad-ogutvalg/nasjonalt-rad-for-ernaering/Tiltak\%20for\%20\%C3\%A5\%20sikre\%20en\%20god\%20vitamin\%20Dstatus\%20i\%20befolkningen\%20IS-1408.pdf/_/attachment/inline/67255a41-60fb-479a-aa18-53dd7bed1bda: 37956cbf2b0d44ba8565ab4e81886e75ffb711d6/Tiltak\%20for\%20\%C3\%A5\%20sikre\%20en\%20god\% 20vitamin\%20D-status\%20i\%20befolkningen\%20IS-1408.pdf (accessed on 25 March 2020).

7. Oberg, J.; Jorde, R.; Almas, B.; Emaus, N.; Grimnes, G. Vitamin D deficiency and lifestyle risk factors in a Norwegian adolescent population. Scand. J. Public Health 2014, 42, 593-602. [CrossRef] [PubMed]

8. The Norwegian Directorate of Health. Available online: https://www.helsedirektoratet.no/retningslinjer/ helsestasjons-og-skolehelsetjenesten/skolehelsetjenesten-520-ar/helseundersokelse-og-helsesamtale/veiing-ogmaling-skolehelsetjenesten-bor-male-vekt-og-hoyde-pa-barn-og-unge (accessed on 30 April 2020).

9. Emmen, J.M.A.; Wielders, J.P.M.; Boer, A.-K.; van den Ouweland, J.M.W.; Vader, H.L. The new Roche Vitamin D Total Assay: Fit for its purpose? Clin. Chem. Lab. Med. 2012, 50, 1969-1972. [CrossRef] [PubMed]

10. Lamberg-Allardt, C.; Brustad, M.; Meyer, H.E.; Steingrimsdottir, L. Vitamin D-A systematic literature review for the 5th edition of the Nordic Nutrition Recommendations. Food Nutr. Res. 2013, 57, 22671. [CrossRef] [PubMed]

11. Munns, C.F.; Shaw, N.; Kiely, M.; Specker, B.L.; Thacher, T.D.; Ozono, K.; Michigami, T.; Tiosano, D.; Mughal, M.Z.; Makitie, O.; et al. Global Consensus Recommendations on Prevention and Management of Nutritional Rickets. J. Clin. Endocrinol. Metab. 2016, 101, 394-415. [CrossRef] [PubMed]

12. Ross, C.A.; Taylor, C.L.; Yaktine, A.L.; Del Valle, H.B. Dietary Reference Intakes for Calcium and Vitamin D; National Academies Press: Washington DC, USA, 2011.

13. Misra, M.; Pacaud, D.; Petryk, A.; Collett-Solberg, P.F.; Kappy, M. The Lawson Wilkins Pediatric Endocrinology Society Drug and Therapeutics Committee Vitamin D deficiency in children and its management: Review of current knowledge and recommendations. Pediatrics 2008, 122, 398-417. [CrossRef] [PubMed]

14. Holick, M.F.; Binkley, N.C.; Bischoff-Ferrari, H.A.; Gordon, C.M.; Hanley, D.A.; Heaney, R.P.; Murad, M.H.; Weaver, C.M.; Endocrine, S. Evaluation, treatment, and prevention of vitamin D deficiency: An Endocrine Society clinical practice guideline. J. Clin. Endocrinol. Metab. 2011, 96, 1911-1930. [CrossRef] [PubMed]

15. Hosmer, D.W.; Lemeshow, S. Applied Logistic Regression, 2nd ed.; John Wiley \& Sons Inc.: New York, NY, USA, 2000.

16. Mansbach, J.M.; Ginde, A.A.; Camargo, C.A., Jr. Serum 25-hydroxyvitamin D levels among US children aged 1 to 11 years: Do children need more vitamin D? Pediatrics 2009, 124, 1404-1410. [CrossRef] [PubMed]

17. Lagunova, Z.; Porojnicu, A.C.; Lindberg, F.A.; Aksnes, L.; Moan, J. Vitamin D status in Norwegian children and adolescents with excess body weight. Pediatr. Diabetes 2011, 12, 120-126. [CrossRef] [PubMed]

18. Plesner, J.L.; Dahl, M.; Fonvig, C.E.; Nielsen, T.R.H.; Kloppenborg, J.T.; Pedersen, O.; Hansen, T.; Holm, J.C. Obesity is associated with vitamin D deficiency in Danish children and adolescents. J. Pediatr. Endocrinol. Metab. 2018, 31, 53-61. [CrossRef] [PubMed] 
19. Hansen, L.B.; Myhre, J.B.; Johansen, A.M.W.; Paulsen, M.M.; Andersen, L.F.; Norwegian Institute of Public Health. Ungkost 3, Landsomfattende kostholdsundersøkelse blant elever i 4. og 8. klasse i Norge. 2015. Available online: https://www.fhi.no/globalassets/dokumenterfiler/rapporter/2017/ungkost-3-rapport-blant9-og-13-aringer_endeligversjon-12-01-17.pdf (accessed on 31 March 2020).

20. Abdel-Wareth, L.; Haq, A.; Turner, A.; Khan, S.; Salem, A.; Mustafa, F.; Hussein, N.; Pallinalakam, F.; Grundy, L.; Patras, G.; et al. Total vitamin D assay comparison of the Roche Diagnostics "Vitamin D total" electrochemiluminescence protein binding assay with the Chromsystems HPLC method in a population with both D2 and D3 forms of vitamin D. Nutrients 2013, 5, 971-980. [CrossRef] [PubMed]

(C) 2020 by the authors. Licensee MDPI, Basel, Switzerland. This article is an open access article distributed under the terms and conditions of the Creative Commons Attribution (CC BY) license (http://creativecommons.org/licenses/by/4.0/). 